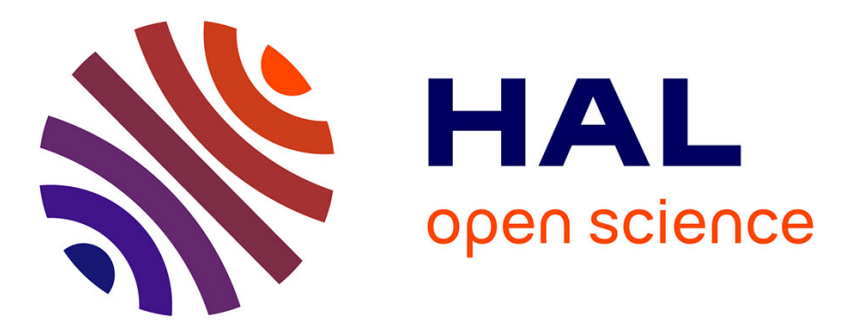

\title{
Hospital discharge data can be used for monitoring procedures and intensive care related to severe maternal morbidity.
}

Anne A. Chantry, Catherine Deneux-Tharaux, Christine Cans, Anne Ego, Catherine Quantin, Marie-Hélène Bouvier-Colle

\section{To cite this version:}

Anne A. Chantry, Catherine Deneux-Tharaux, Christine Cans, Anne Ego, Catherine Quantin, et al.. Hospital discharge data can be used for monitoring procedures and intensive care related to severe maternal morbidity.: Validity of obstetric hospital discharge data. Journal of Clinical Epidemiology, 2011, 64 (9), pp.1014-22. 10.1016/j.jclinepi.2010.11.015 . inserm-00574115

\section{HAL Id: inserm-00574115 https://www.hal.inserm.fr/inserm-00574115}

Submitted on 7 Mar 2011

HAL is a multi-disciplinary open access archive for the deposit and dissemination of scientific research documents, whether they are published or not. The documents may come from teaching and research institutions in France or abroad, or from public or private research centers.
L'archive ouverte pluridisciplinaire HAL, est destinée au dépôt et à la diffusion de documents scientifiques de niveau recherche, publiés ou non, émanant des établissements d'enseignement et de recherche français ou étrangers, des laboratoires publics ou privés. 


\section{Hospital discharge data can be used for monitoring procedures and intensive care related to severe maternal morbidity.}

Anne A. Chantry ${ }^{1,2}$, Catherine Deneux-Tharaux ${ }^{1,2}$, Christine Cans ${ }^{3}$, Anne Ego ${ }^{1,4}$, Catherine Quantin ${ }^{5,6}$, Marie-Hélène Bouvier-Colle ${ }^{1,2}$ for the GRACE study group*.

${ }^{1}$ INSERM, UMR S953, Epidemiological research on perinatal health and women's and children's health, F-75020, Paris, France.

2 UPMC Univ Paris 06, UMR S 953, F-75005, Paris, France.

${ }^{3}$ CHRU Grenoble, Public Health Department, F-38000, Grenoble, France.

${ }^{4}$ CHRU Lille, Medical Evaluation Unit, The Jeanne de Flandre Maternity Hospital, F-59000, Lille, France.

${ }^{5}$ INSERM, U866,Lipids, nutrition, cancer, F-21000, Dijon, France.

${ }^{6}$ UB, Univ Bourgogne, F-21000, Dijon, France

*GRACE study group: G. Bal, G. Beucher, MJ. D'alche Gautier, AS. Ducloy-Bouthors, N. Lamendour, I. Le Fur, V. Tessier, J. Zeitlin.

\section{Corresponding author:}

Anne A. CHANTRY

Address: INSERM U953 Hôpital TENON - Bâtiment Recherche - 4 rue de la Chine -75020

PARIS, France

Telephone: +33156018369

E-mail: anne.chantry@inserm.fr 


\section{Abstract}

3 Objective: To estimate the accuracy and reliability of the reporting of diagnoses and

4 procedures related to severe acute maternal morbidity in French hospital discharge data.

6 Study design and setting: The study, conducted in four French tertiary teaching hospitals, 7 covered the years 2006 and 2007 and 30,607 deliveries. We identified severe maternal 8 morbid events - eclampsia, pulmonary embolism, procedures related to postpartum 9 hemorrhages, and intensive care - in administrative hospital discharge data and medical 10 records and compared their recording. Information from medical records was the gold 11 standard. Sensitivity, specificity, positive and negative predictive values of the hospital 12 discharge data for these events were calculated. False positives and false negatives were 13 examined to identify the reasons for misrecorded information.

15 Results: The positive predictive value of the hospital discharge data was $20 \%$ for eclampsia. 16 For procedures related to postpartum hemorrhages, their positive predictive values were 17 high, but sensitivities were lower; however, $95 \%$ of recording errors could be corrected. All 18 indicators for intensive care exceeded $98 \%$.

20 Conclusion: Intensive care and procedures seem reliably reported in the hospital 21 administrative database, which therefore can be used to monitor them. Use these data for 22 monitoring diagnoses will require a greater investment by clinicians in the accuracy of their 23 reporting.

25 Key words: Severe maternal morbidity - Hospital discharge data - Validity - Sensitivity 26 Positive predictive value - Medical records.

27 Running title: Validity of obstetric hospital discharge data.

28 Word count: 200 words. 


\section{What is new ?}

30

$31 \quad-$ Key finding

32 Intensive care and procedures for postpartum hemorrhages seem reliably and accurately

33 reported in the hospital discharge database.

$35 \quad$ - What this adds to what we know?

36 Hospital discharge data could be used for monitoring several events related to severe

37 maternal morbidity.

38

$39 \quad$ - What should change now?

40 Monitoring diagnoses in hospital discharge databases will require a greater investment by

41 clinicians in the accuracy of their reporting and regular internal quality controls. 
45 Hospital administrative databases are a useful tool for measuring hospital activity [1]. They

46 are employed to define health priorities, assess the costs of providing health care, and

47 optimize the organization of healthcare facilities [2,3]. For some 20 years, these routinely

48 collected data have also been used for research purposes to measure disease incidence

$49[4,5]$ or procedure frequencies, assess the rate of complications of hospitalizations or surgery

$50 \quad[6,7]$ and identify the determinants of medical conditions [8-10]. The validity of these data

51 depends simultaneously on the reliability of the information recorded and the accuracy of

52 their coding at different stages of processing. Studies to validate hospital administrative data

53 in the United States [11,12], Canada [6], Australia $[9,10,13]$ and Scandinavia $[5,14,15]$ have

54 generally concluded that they can be used, but underline their numerous limitations,

55 including substantial inter-facility variability in coding quality [16-19], better coding for more

56 serious complications and diseases [7,20], and better recording of procedures than

57 diagnoses [16,21,22]. Most reports on the validation of these data come from English-

58 speaking countries. They are relatively sparse in Europe. Such studies in France have

59 covered the fields of oncology $[4,10,23,24]$, intensive care [25] and vascular disease [26], but

60 not obstetrics.

61 Routine childbirth in France takes place within the hospital system. Although no disease is

62 present in most obstetric hospitalizations, a non-negligible but unknown number involve

63 complications of pregnancy, delivery or the postpartum period. Today, changing trends in

64 obstetric practices and in maternal profiles require the development of indicators that can

65 measure and monitor severe maternal morbidity.

66 Hospital databases are a potential tool for estimating the frequency of severe maternal

67 morbidity and following its trends over time because women with such morbidity are always

68 hospitalized and administrative records are supposedly exhaustive, rapidly available and 
69 inexpensive to use. However, before this information can be used, its validity must be

70 assessed.

71 Several studies in Australia and in the USA sought to validate hospital discharge data for 72 numerous obstetrical complications (as many as 50) [13], or on the contrary, have 73 concentrated on only one or two $[20,27,28]$. Because there is no consensual definition for 74 severe maternal morbidity, we focused on the severe maternal morbid events (SMME) that 75 are the most frequent causes of maternal mortality [29-31].

76 Our objective was to study the validity of French hospital discharge data from the 77 Programme of Medicalization of Information System (PMSI) for some SMME. More 78 specifically, our aim was to evaluate whether the SMME were transcribed in the PMSI as 79 they were described in the medical records.

\section{$81 \quad$ Material \& methods}

84 Inspired by the American DRG (diagnosis-related groups) model [2], the PMSI was 85 established in France in 1991 [3] and extended in 1997 to all French healthcare facilities [32]. 86 Initially designed to analyze hospital activity and contribute to the strategic elaboration of 87 facility plans, it has become an instrument of financial management. Since 2008, each 88 hospital's budget has depended on the medical activity described in this PMSI [33], which 89 compiles discharge abstracts for every admission. Information in these abstracts is 90 anonymous and covers both administrative (age, sex, geographic code of residence, year, 91 month and type of admission, year, month, and type of discharge, facility status) and medical 92 data. Diagnoses identified during the admission are coded according to the 10th edition of 93 the International Classification of Diseases (ICD10). The condition occasioning the greatest 94 use of resources during the hospitalization is recorded as the main diagnosis, with other 95 diseases listed as associated diagnoses [34]. All procedures performed during the 96 hospitalization are coded according to the French Common Classification of Medical 
97 Procedures (CCAM). PMSI rules are national and imposed by the government. Each facility 98 produces its own anonymous standardized data, which are then compiled at the national 99 level. Our validation study was conducted on this PMSI database.

100

101 Selection of the study population

102 First, PMSI abstracts from the four study hospitals (Caen, Cochin [AP-HP, Paris], Grenoble 103 and Lille, university hospitals) were extracted from the national database. Then, we selected 104 hospitalizations of women of reproductive age (14 to 50), with at least one code related to 105 pregnancy, delivery, or the postpartum period, and who were discharged from 1 January 1062006 through 31 December 2007 (Figure 1). Women who did not give birth in one of the 107 study hospitals were excluded because the content of their medical records was incomplete.

109 Selection of hospitalizations

110 Within the selected PMSI database (=64,061 abstracts), we identified abstracts including at 111 least one of the following SMME: diagnosis of eclampsia; diagnosis of pulmonary embolism; 112 one of the following procedures for treating postpartum hemorrhages: uterine artery 113 embolization, uterine artery ligation, uterine vascular pedicle ligation, or hysterectomy; or 114 finally, intensive care. In the PMSI, the intensive care variable is defined by admission to 115 intensive care unit and/or a simplified acute physiology score (SAPS II) $\geq 15$ associated with 116 at least one specific procedure. The hospitalizations were selected from the PMSI by 117 searching for specific codes for each of these SMME (figure 1) which occurred during the

118 whole maternal risk period as defined by the WHO (pregnancy, delivery and post-partum).

119 When several abstracts described the same event for the same woman, the event was 120 counted only once.

122 Validation of the PMSI recorded data

123 The medical record was considered to be the gold standard. The term or name of each of the 124 SMME under study was used to search for it in the medical records. 
125 The SMME identification in the medical records was made possible by querying an additional

126 database: the database of computerized medical records available in all four centers. For $1272006-2007,30,614$ deliveries were recorded in this database. In centers 1 and 3, the medical 128 records and computerized medical records were combined. In centers 2 and 4, the 129 computerized records consisted of a complementary database where information was 130 entered daily by clinicians during hospitalization. SMME were identified in the computerized 131 databases by searching for their terms.

132 This computerized medical records database has been linked with the database extracted 133 from the PMSI using the following variables: patient's age, month and type of admission to 134 hospital, month and type of discharge, length of stay and geographic code of residence.

135 The cases selected from the PMSI were compared with the data from the matching medical 136 records. This comparison involved a simple reading of the source medical record with all its 137 components: discharge letters (to referring and primary care physicians), nursing records, 138 hospital and surgical reports. Specifically, we did not interpret any examinations or judge any 139 diagnoses. The SMME we sought was either specifically mentioned in the record or it was 140 not.

141 The true positives were the SMME identified simultaneously in the PMSI abstracts and in the 142 corresponding medical records. Inversely, false positives were events recorded in the PMSI 143 that did not exist as such in the patients' records.

144 False negatives were the SMME experienced by patients and listed in their medical records, 145 but not reported in the PMSI. On the contrary, true negatives corresponded to all the 146 situations in which no SMME was listed in either the patient's record or the PMSI abstract.

147 The causes of both false positives and false negatives were further analyzed by reading the 148 complete medical chart and examining all the codes of the hospital discharge abstract.

150 The National Data Protection Authority (Commission Nationale de l'Informatique et des 151 Libertés) approved the study ( $\left.n^{\circ} 1004749\right)$. 


\section{$153 \quad$ Statistical analyses}

154 To estimate the accuracy and reliability of the PMSI database for the SMME studied, we 155 analyzed sensitivity, specificity, positive predictive value (PPV), and negative predictive value 156 (NPV) of the PMSI data relative to the source medical records.

157 Sensitivity was the probability that PMSI data correctly identified a woman with a SMME; 158 specificity was the probability that PMSI data correctly identified a woman with no SMME.

159 The PPV corresponded to the probability that a woman had a SMME given that SMME was 160 also coded in the PMSI. The NPV, on the other hand, was the probability that a woman had 161 not a SMME given SMME was also not coded in the PMSI.

162 Cohen kappa scores were calculated to assess the degree of agreement between the two 163 databases, taking random agreement into account. The Kappa score proposes a neutral 164 description of the agreement between the two data sources for each event, without 165 attributing more importance to the database serving as a reference for the other analyses. 166 Excellent agreement was defined as a score greater than 0.80 , substantial from 0.80 to 0.60 , 167 moderate from 0.59 to 0.40 , and poor below 0.40 [35]. Confidence intervals $(\mathrm{Cl})$ were 168 determined with a type I risk of $5 \%$.

\section{$170 \quad$ Results}

172 For 2006-2007, among the 64,061 PMSI abstracts, 1,022 abstracts identified an SMME. 173 After the study of duplicates, 403 single SMME were identified in the PMSI.

174 In the PMSI, the three most frequent SMME were, in decreasing order: intensive care, 175 eclampsia, and embolizations (Table 1). Comparison with the content of the corresponding 176 medical files validated 314 SMME of the 403 identified in the PMSI. After validation, the order 177 of frequency was modified, and eclampsia moved from the second most frequent event in the $178 \quad$ PMSI to the least frequent. 
180 Considering the study population of 30,614 women who delivered during the study period,

181 the analysis of the false positives and false negatives in the PMSI showed three distinct

182 situations: a high proportion of false positives for diagnoses, false negatives for procedures,

183 and few false positives or negatives for intensive care (Table 1).

184 The rate of false positives was $80 \%$ for eclampsia. Analysis of the medical records failed to 185 validate 67 of the 84 cases of eclampsia identified in the PMSI. Similarly, $36 \%$ of the 186 pulmonary embolisms, that is, 11 of 31 recorded in the PMSI, were not confirmed in the 187 medical records.

188 There was only one case of false positive for postpartum hemorrhage procedures, for 1 of 189 the 34 ligations mentioned in the PMSI. However, the proportion of false negatives for 190 procedures was $44 \%$ for embolizations and $25 \%$ for hysterectomies and ligations. Overall, 56

191 embolizations, 8 hysterectomies and 11 ligations were not identified in the PMSI.

192 The PMSI and the medical records listed the same number of cases receiving intensive care, 193 although there were three false positives and three false negatives.

194 For seven SMME identified in the PMSI, the corresponding computerized file was empty, and 195 the accuracy of the information could not be checked. Consequently, these cases could not 196 be classified as either true or false positive, and their status is described as "uncertain" 197 (Table 1). This concerned five eclampsia and two embolisations.

199 The analysis of the content of medical records showed that the false positives for eclampsia 200 in the PMSI corresponded to less severe situations, such as preeclampsia, isolated 201 gestational hypertension or isolated proteinuria. The study of the PMSI false negatives for 202 procedures found that $95 \%$ of them (71/75) were due to inappropriate coding of procedures 203 for postpartum hemorrhage management that were mentioned in the PMSI but with codes 204 not specific to the postpartum period. For example, medical records reported emergency 205 hysterectomies for massive postpartum hemorrhage, whereas the corresponding PMSI 206 abstract coded for a planned hysterectomy in a non-obstetric context (CCAM code JFKA015 207 instead of JNFA001). Another frequent error was miscoding of embolization of uterine 
208 arteries for postpartum hemorrhage as embolization conducted as a preoperative phase for

209 oncologic surgery, outside of pregnancy.

211 Table 2 presents the values of the indicators calculated for the PMSI, with the medical 212 records as the reference, by type of SMME.

213 Because the PMSI had numerous false positive errors for eclampsia, its PPV for this disease 214 was low, only $20 \%$. Its PPV for pulmonary embolism was $65 \%$. On the contrary, the PMSI 215 was highly sensitive for these diagnoses, respectively, $85 \%$ and $83 \%$. Inversely, the PPVs of 216 the PMSI for procedures were very high, ranging from $97 \%$ to $100 \%$, although values for 217 sensitivities ranged from $56 \%$ to $75 \%$, reflecting the false negative errors found in the 218 preceding analysis. We considered these false negatives for procedures rectifiable since the 219 context of pregnancy/delivery could be identified through other codes contained in the PMSI 220 abstracts. In consequence, we secondarily considered these records as true positive cases 221 of SMME in PMSI, and recalculated revised estimates for the validity indices (Table 2). The 222 revised sensitivities of the PMSI exceeded 95\% for embolizations as for ligations, and 223 reached $100 \%$ for hysterectomies.

224 For intensive care, the sensitivity, specificity, PPV and NPV of the PMSI all exceeded 98\% 225 and the kappa score was close to 1.

226 Sensitivity analyses were conducted to evaluate the impact on the calculated indicators of 227 the seven PMSI SMME cases for which the accuracy of information could not be checked in 228 the medical records, and showed similar results.

230 The results by center point out two particular situations (Table 3 ). In centers 1 and 2, the 231 sensitivity, specificity, PPV and NPV of the PMSI data were greater than $80 \%$ for identifying 232 SMME. On the other hand, SMME were recorded less accurately in centers 3 and 4 . In 233 center 3 where most of the mis-coding errors for embolizations were found, the sensitivity of 234 the PMSI data greatly improved after correction of these codes. In center 4 , the sensitivity of 235 the PMSI data also improved after correction of procedures codes not specific to the 
236 obstetrical context, but its 57\% PPV reflected the large number of false positives found for 237 cases of eclampsia in this facility.

\section{Discussion}

241 This validation study of French hospital discharge database for severe maternal morbidity 242 shows a various quality of data according to the types of event and centers. The PMSI 243 appears to overreport diagnoses, although procedures are reported correctly on the whole. 244 PMSI reporting of intensive care is very reliable. Two hospitals correctly transcribed their 245 SMME data in hospital discharge abstracts, whereas two others require improvements: one 246 for false negatives, the other because of false positives.

248 Our study has several limitations. First, there is no consensual definition of severe maternal 249 morbidity. Our selected SMME do not cover all types of maternal morbidity, but they do cover 250 those that are the most frequent causes of maternal deaths [29-31]. In addition, our 251 combination of events makes it possible to analyze the validity of various types of hospital 252 data, namely diagnoses, procedures and management codes.

253 The type of hospitals selected might have resulted in selection bias. All are tertiary teaching 254 hospitals, chosen because they treat the most severe cases of maternal morbidity in their 255 regions. Even though SMME are, obviously, not exclusive to these tertiary hospitals, this type 256 of facility, which concentrates SMME, remains best for an initial study of PMSI validity related 257 to severe maternal morbidity, given the low expected frequency of these events. Hsia et al. 258 showed in a different context and field that data from small non-university hospitals are not 259 reliable [11]. Inversely, lezzoni et al. argued that level III hospitals, because they handle 260 more complex cases, face greater difficulties in coding and may thus make more frequent 261 errors [17]. In the obstetric field, Lydon-Rochelle et al. [36] found that type II maternity units 262 (average size and able to care for moderately serious situations) have the most reliable 
263 hospital discharge databases. Di Giuseppe et al. found no difference in data validity

264 according to hospital size in a study of 20 maternity units [37].

265 The number of centers included in our study is small, and each has its own organization 266 regarding collection and coding of hospital discharge data. Despite the national rules for 267 treatment of these medical data, the quality of their PMSI differed. In our study, it is not the 268 PMSI data processing system that seems inappropriate for dealing with severe maternal 269 morbidity, but rather the rigor and quality of its application within each facility. This limitation 270 prevents us from generalizing our results to the national level. However, this issue is less 271 relevant for intensive care because the great majority of intensive care units are located in 272 teaching hospitals; moreover, the intensive care variable is less error-prone due to its 273 particular coding rules.

274 Our objective was to study the validity of the PMSI database for some SMME. More 275 specifically, our aim was to know how accurately the PMSI database reflected diagnoses 276 made and procedures performed by the team in charge of the case. In that context, we did 277 not reinterpret a posteriori the whole medical information like other authors did [6$27814,16,17,22,27,38-40]$, but we evaluated whether the SMME were transcribed in the PMSI as 279 they were described in the medical records. Therefore, our study is based on the comparison 280 of existing records, and the gold standard is represented by the diagnoses which justified 281 and generated a specific management. In a different perspective, a study assessing the 282 accuracy of diagnoses recorded in a series of randomly selected source medical files, by 283 using a blinded recoding by experts would provide complementary information.

285 The use of computerized medical files was required to search easily and inexpensively for 286 SMME that were described in records but not reported in the PMSI (false negatives). In half 287 of the centers ( $n^{\circ} 1$ and 3 ), these computerized medical files were the actual entire and only 288 medical record. The search for false negatives in the PMSI was thus possible and even easy. 289 In the other two centers ( $\mathrm{n}^{\circ} 2$ and 4$)$, the computerized medical files were a supplementary 290 document, completed bit by bit by the clinicians during the course of the hospitalization, and 
291 verified daily by midwives specifically assigned to this function. They might therefore be 292 considered a relevant source for false negatives searching. Our method therefore simplified 293 the study of false negatives and allowed us to estimate the validity of PMSI coding for the

294 SMME in a large sample of more than 30,000 deliveries. Nonetheless, it is possible that 295 some SMME were not entered in the source medical record or in the computerized files. 296 These false negatives may not have been identified, their number may have been 297 underestimated, and consequently the sensitivities overestimated. It would have been 298 possible to randomly sample hospitalizations to estimate the false negative rate in the 299 medical records. Because SMME are rare events, however, to be valid, this method would 300 have had to include a very large sample. The cost/benefit ratio of such a study appeared 301 quite negative to us, and we did not chose this option.

302 However, in the two centers with complementary computerized medical files, midwives daily 303 verify all the information reported in the computerized medical records, thereby minimizing 304 the risk of errors and oversights. In addition, according to Altman, serious events are seldom 305 forgotten during coding [41]. Thus, although this bias should be borne in mind, it is likely to 306 remain marginal.

308 The analyses of the diagnoses in the PMSI show that their coding validity is poor. The 309 numerous false positives indicate that diagnoses are overreported in the discharge abstracts. 310 The low PPV of the PMSI for eclampsia - 20.2\% - means that in this database, most so311 called eclampsia cases are not. Detailed examination showed that these cases were instead 312 severe preeclampsia or HELLP syndrome. Such coding errors are not unusual. Other 313 authors have found PPVs for eclampsia in hospital databases ranging from $23.5 \%$ in an 314 Australian multicenter study [13,39] to $41.7 \%$ for single-center study in Chicago [28], and $31550 \%$ for a statewide validation in Washington [36].

316 Several factors may explain the overreporting or upcoding of diagnoses in hospital 317 databases. First, the large variety of participants of diverse skill levels involved in coding 318 leads to heterogeneity in the quality of the medical information $[15,18,36,40,42,43]$. Second, 
319 the most serious cases, which involved the mobilization of the entire medical team, may be

320 overcoded to indicate the seriousness of situation [39,40,44,45]. Finally, the payment system

321 based on severity of diagnosis is a strong incentive to overcoding, that is, it increases

322 remuneration for the hospital $[11,43,46,47]$. Our study confirmed these hypotheses for

323 eclampsia and pulmonary embolisms. Coding at all four hospitals was routinely performed by

324 employees with widely heterogeneous skill levels and with little or no training in this quite

325 particular task: nurses, midwives, interns, residents, and sometimes even secretaries or

326 students. Also in all centers, the cases of severe preeclampsia or deep venous thrombosis

327 overcoded as eclampsia or pulmonary embolism corresponded to cases with prolonged

328 hospitalizations or severe illness that required major and expensive treatment.

330 On the other hand, the high positive predictive value of the PMSI data for procedures 331 indicates that these are not overreported. Analysis of the procedures does not show false 332 positives but rather some false negatives, indicating moderate underreporting of their true 333 number in the PMSI. The sensitivity of the PMSI for the procedures therefore varies. It is 334 relatively elevated for hysterectomies and ligations (close to $75 \%$ ), but lower (56\%) for 335 embolizations. An Australian multicenter study on the validity of administrative databases 336 found a sensitivity of $28.3 \%$ for hysterectomy data in the context of postpartum hemorrhage 337 and attributed this result to specific coding errors $[13,20]$. The quality of reporting is better in 338 our study, but the same type of errors is still present. These errors, first mentioned in the 339 1990s [12,42-44] and reported still today [20,22], are the consequence of using a 340 classification that is ever more specific and increasingly complicated Coding becomes 341 extremely time-consuming, thus inciting physicians to record procedures in the hospital 342 databases with the code they use most often, even though perfectly appropriate codes exist 343 for the specific situation. A similar problem is seen with the use of the "thesaurus", a 344 summary of codes of procedures performed regularly in the department, which facilitates 345 coding, but does not describe rare and severe situations correctly [22,42]. Demlo $[44,45]$ 
346 predicted this type of problem at the implementation of the system of health-related 347 administrative databases in the United States in the early 1980s.

348 In our study, most of these false negatives could be easily identified because the hospital 349 discharge summaries with the non-specific procedure code also contained codes indicating 350 the context of pregnancy/delivery. In consequence, such a correction could be introduced in 351 routine, Overall, the high PPV and sensitivity of the PMSI for most of the procedures studied 352 indicates that their coding is relatively valid and that errors are rectifiable. In these conditions, 353 it appears acceptable to us to monitor their frequencies from the PMSI.

355 Our findings are consistent with those from international studies that validated similar types 356 of databases. In obstetrics as in other field, the coding in hospital databases is more reliable 357 for procedures than for diagnoses $[16,19-22,38]$. This research appears to us to be an 358 essential prerequisite to any use of administrative databases. Nonetheless, because they are 359 easy to access, they are regularly used in hospital departments for research purposes, 360 without validation. Erroneous data leading to biased results, incorrect conclusions and thus 361 flawed proposals cannot improve either quality of care or patient health. Like Pollock and 362 Hadfield $[10,48]$, we hope that other teams across the world will make an effort to validate 363 their hospital administrative data, especially in the field of severe maternal morbidity, to 364 facilitate comparisons between countries. An original aspect of our study is to have sought to validate the coding for intensive care in 367 hospital data. Their sensitivity, specificity, PPV and NPV in the PMSI are very high (>98\%). 368 Related PMSI data are both accurate and reliable. In obstetrics, such intensive care can 369 therefore be used as a marker of the severity of maternal morbidity, and our results are the 370 first to show its validity.

372 Our study is one of the first to estimate the validity of hospital administrative databases in 373 Europe $[15,19,26]$. Although the only moderate validity of the hospital data means that 
374 research cannot be based exclusively on them, it appears likely that the system in France will

375 improve. Because the reimbursement of medical services is directly correlated with PMSI

376 data, the national health insurance fund is multiplying external audits to identify coding errors

377 and overcoding. Facilities where abuses are identified will be required to reimburse

378 payments for unjustified services. The increase in these external quality controls, in addition

379 to the internal controls organized by the hospitals, should surely lead to improvements in

380 data quality.

382 Conclusion

383 Hospital discharge data can be used for monitoring the frequencies of procedures for 384 postpartum hemorrhages and intensive care related to severe maternal morbidity. The 385 utilization of PMSI data about diagnoses will require a greater investment by clinicians in the 386 accuracy of their reporting and regular internal quality controls.

389 Count of words : 4,013 words.

$392 \quad$ Acknowledgments

393 This study was funded by the IReSP (French Research Institute of Public Health) and Anne

394 Chantry was supported by a doctoral grant from the French Ministry of Research. The 395 authors thank all the members of the Grace study group and Annick Blondel, Maïté Mériaux, 396 Julie Tort for their participation.

$400 \quad$ Titles of figure and tables:

401

402 - Figure 1 - Algorithm for selection of the PMSI abstracts 
403 - Table 1 - Severe maternal morbid events (SMME) identified in the PMSI database and in 404 the medical records, 4 centers, 2006-2007: number, false positives and false negatives *.

405 - Table 2 - Validity of the PMSI data for severe maternal morbid events (SMME): kappa

406 score, sensitivity, specificity, positive predictive value (PPV) and negative predictive value

$407 \quad(\mathrm{NPV})$ *.

408 - Table 3 - Validity of the PMSI data for severe maternal morbid events (SMME), per center:

409 sensitivity, specificity, positive predictive value (PPV) and negative predictive value (NPV) *

410 


\section{References}

413 1. MINISTERE DE LA SANTE. Décret n`94-666 du 27 juillet 1994 relatif aux systèmes 414 d'information médicale et à l'analyse de l'activité des établissements de santé publics 415 et privés. In, Journal Officiel de la République Française, n¹80 du 5 août 1994. $416 \quad$ Paris; $1994: 11395$

417 2. Fetter RB, Shin Y, Freeman JL, Averill RF, Thompson JD. Case mix definition by 418 diagnosis-related groups. Med Care 1980;18:iii, 1-53

419 3. MINISTERE DE LA SANTE. Loi n`94-748 du 31 Juillet 1991 portant réforme 420 hospitalière. In, Journal Officiel de la République Française, nº 179 du 2 août 1991. $421 \quad$ Paris; 1991:10255

422 4. Couris CM, Polazzi S, Olive F, et al. Breast cancer incidence using administrative data: correction with sensitivity and specificity. J Clin Epidemiol 2009;62:660-666

5. Mahonen M, Salomaa V, Keskimaki I, et al. The feasibility of combining data from

6. Quan H, Parsons GA, Ghali WA. Assessing accuracy of diagnosis-type indicators for flagging complications in administrative data. J Clin Epidemiol 2004;57:366-372

8. Humphries $\mathrm{KH}$, Rankin JM, Carere RG, et al. Co-morbidity data in outcomes research: are clinical data derived from administrative databases a reliable alternative to chart review? J Clin Epidemiol 2000;53:343-349

7. Quan H, Parsons GA, Ghali WA. Validity of procedure codes in International Classification of Diseases, 9th revision, clinical modification administrative data. Med Care $2004 ; 42: 801-809$ 
438 10. Hadfield RM, Lain SJ, Cameron CA, et al. The prevalence of maternal medical 439 conditions during pregnancy and a validation of their reporting in hospital discharge $440 \quad$ data. Aust N Z J Obstet Gynaecol 2008;48:78-82

441 11. Hsia DC, Krushat WM, Fagan AB, Tebbutt JA, Kusserow RP. Accuracy of diagnostic coding for Medicare patients under the prospective-payment system. $\mathrm{N}$ Engl J Med 1988;318:352-355

12. Lloyd SS, Rissing JP. Physician and coding errors in patient records. JAMA $1985 ; 254: 1330-1336$

14. Klemmensen AK, Olsen SF, Osterdal ML, Tabor A. Validity of preeclampsia-related diagnoses recorded in a national hospital registry and in a postpartum interview of the women. Am J Epidemiol 2007;166:117-124

15. Klemmensen AK, Olsen SF, Wengel CM, Tabor A. Diagnostic criteria and reporting procedures for pre-eclampsia: a national survey among obstetrical departments in Denmark. Eur J Obstet Gynecol Reprod Biol 2005;123:41-45

16. Fisher ES, Whaley FS, Krushat WM, et al. The accuracy of Medicare's hospital claims

17. Iezzoni LI, Burnside S, Sickles L, et al. Coding of acute myocardial infarction. Clinical and policy implications. Ann Intern Med 1988;109:745-751

460 18. Smulian JC, Ananth CV, Hanley ML, et al. New Jersey's electronic birth certificate program: variations in data sources. Am J Public Health 2001;91:814-816 data: progress has been made, but problems remain. Am $\mathrm{J}$ Public Health 1992;82:243-248 
20. Lain SJ, Roberts CL, Hadfield RM, Bell JC, Morris JM. How accurate is the reporting of obstetric haemorrhage in hospital discharge data? A validation study. Aust $\mathrm{N} \mathrm{Z} \mathrm{J}$ Obstet Gynaecol 2008;48:481-484

21. Campbell SE, Campbell MK, Grimshaw JM, Walker AE. A systematic review of discharge coding accuracy. J Public Health Med 2001;23:205-211

22. Yasmeen S, Romano PS, Schembri ME, Keyzer JM, Gilbert WM. Accuracy of obstetric diagnoses and procedures in hospital discharge data. Am J Obstet Gynecol 2006;194:992-1001

23. Carre N, Uhry Z, Velten M, et al. [Predictive value and sensibility of hospital discharge

25. Misset B, Nakache D, Vesin A, et al. Reliability of diagnostic coding in intensive care patients. Crit Care 2008;12:R95

26. Casez P, Labarere J, Sevestre MA, et al. ICD-10 hospital discharge diagnosis codes were sensitive for identifying pulmonary embolism but not deep vein thrombosis. $J$ Clin Epidemiol 2010;63:790-97

27. Romano PS, Yasmeen S, Schembri ME, Keyzer JM, Gilbert WM. Coding of perineal

29. Bouvier-Colle MH, Salanave B, Ancel PY, et al. Obstetric patients treated in intensive lacerations and other complications of obstetric care in hospital discharge data. Obstet Gynecol 2005;106:717-725

28. Geller SE, Ahmed S, Brown ML, et al. International Classification of Diseases-9th revision coding for preeclampsia: how accurate is it? Am J Obstet Gynecol 2004;190:1629-1633; discussion 1633-1624

care units and maternal mortality. Regional Teams for the Survey. Eur J Obstet Gynecol Reprod Biol 1996;65:121-125 
493 30. National Comittee of the experts on maternal mortality. Report of the national comittee of the experts on maternal mortality,1995-2001. In. Paris: INSERM - INVS; 2006

31. National Comittee of the experts on maternal mortality. Report of the national comittee of the experts on maternal mortality, 2001-2006. In. Paris: INSERM - INVS;

32. MINISTERE DE LA SANTE. Arrêté du 22 juillet 1996 relatif au recueil et au traitement des données d'activité médicale. In, Journal Officiel de la République Française, n¹73 du 26 juillet 1996. Paris; 1996:11308

34. MINISTERE DE LA SANTE. Circulaire $\mathrm{n}^{\circ} 119$ du 4 octobre 1985 relative à la mise en place dans les établissements hospitaliers des résumés de sortie standardisés (RSS). In, Bulletin officiel du ministère chargé de la santé n 90/2 bis Paris; 1989:2971

35. Landis JR, Koch GG. The measurement of observer agreement for categorical data.

36. Lydon-Rochelle MT, Holt VL, Cardenas V, et al. The reporting of pre-existing maternal medical conditions and complications of pregnancy on birth certificates and in hospital discharge data. Am J Obstet Gynecol 2005;193:125-134

38. Thornton C, Makris A, Ogle R, Hennessy A. Generic obstetric database systems are unreliable for reporting the hypertensive disorders of pregnancy. Aust $\mathrm{N} Z \mathrm{~J}$ Obstet Gynaecol 2004;44:505-509 
520 39. Roberts CL, Bell JC, Ford JB, et al. The accuracy of reporting of the hypertensive disorders of pregnancy in population health data. Hypertens Pregnancy 2008;27:285297

40. Lydon-Rochelle MT, Holt VL, Nelson JC, et al. Accuracy of reporting maternal inhospital diagnoses and intrapartum procedures in Washington State linked birth records. Paediatr Perinat Epidemiol 2005;19:460-471

41. Altman D, Bland JM. Confidence intervals illuminate absence of evidence. BMJ 2004;328:1016-1017

42. Dussaucy A, Viel JF, Mulin B, Euvrard J. [The framework Prospective Payment Information Systems: bias, sources of errors and consequences]. Rev Epidemiol Sante Publique 1994;42:345-358

44. Demlo LK, Campbell PM. Improving hospital discharge data: lessons from the National Hospital Discharge Survey. Med Care 1981;19:1030-1040

45. Demlo LK, Campbell PM, Brown SS. Reliability of information abstracted from patients' medical records. Med Care 1978;16:995-1005

47. Lombrail P, Minvielle E, Comar L, Gottot S. [Prospective Payment Information Systems and epidemiology: a difficult link to establish]. Rev Epidemiol Sante Publique

544 48. Pollock W, Sullivan E, Nelson S, King J. Capacity to monitor severe maternal morbidity in Australia. Aust N Z J Obstet Gynaecol 2008;48:17-25 
Abstracts with :

0 discharge date from $01 / 01 / 06$ through 12/31/07

$n=2822,658$

- a code for principal or associated diagnosis in chapter $O$ (obstetrics chapter in ICD 10) or equal to Z35, Z37, Z39 *

$\circ$ reproductive age women (14 to 50)

Abstracts from Caen, Cochin (Paris), Grenoble and Lille tertiary university hospitals

Abstracts of women who gave birth in the four centers

Abstracts including at least one of the following codes

$\mathrm{n}=1,022$

- Pregnancy, puerperium or postpartum eclampsia

(PMSI ICD 10 code: 015)

- Pregnancy or postpartum pulmonary embolism,

(PMSI ICD 10 code: 088)

$\circ$

Postpartum hemorrhage uterine artery embolization, (PMSI CCAM code: EDS011)

○ Postpartum hemorrhage hysterectomy, (PMSI CCAM code: JNFA001)

- Postpartum hemorrhage hypogastric artery ligation,

(PMSI CCAM code: EDSA002)

- Postpartum hemorrhage uterine vascular pedicle ligation,

- Intensive care ** (PMSI CCAM code: ELSA002)

(PMSI code : SUPSI and SUPREA) 
Table 1 - Severe maternal morbid events (SMME) identified in the PMSI database and in the medical records, 4 centers, 2006-2007 : number, false positives and false negatives *.

\begin{tabular}{|c|c|c|c|c|c|c|}
\hline & $\begin{array}{c}\text { Single SMME } \\
\text { identified in } \\
\text { PMSI }\end{array}$ & $\begin{array}{l}\text { SMME in } \\
\text { medical } \\
\text { records }\end{array}$ & $\begin{array}{c}\text { SMME } \\
\text { identifed in } \\
\text { PMSI and } \\
\text { validated in } \\
\text { medical } \\
\text { records }\end{array}$ & $\begin{array}{c}\text { False- } \\
\text { positives }\end{array}$ & $\begin{array}{c}\text { False- } \\
\text { negatives }\end{array}$ & $\begin{array}{l}\text { Uncertain } \\
\text { status }\end{array}$ \\
\hline & $n(\%)$ & $n(\%)$ & $n(\%)$ & $\mathrm{n}$ & $\mathrm{n}$ & $\mathrm{n}$ \\
\hline Total & $403(100 \%)$ & $399(100 \%)$ & $314(100 \%)$ & 82 & 85 & 7 \\
\hline Eclampsia & $89(22)$ & $20(5)$ & $17(5)$ & 67 & 3 & 5 \\
\hline $\begin{array}{l}\text { Pulmonary } \\
\text { embolism }\end{array}$ & $33(8)$ & $24(6)$ & $20(6)$ & 11 & 4 & 2 \\
\hline $\begin{array}{l}\text { Uterine artery } \\
\text { embolization }\end{array}$ & $72(18)$ & $128(32)$ & $72(23)$ & 0 & 56 & - \\
\hline Hysterectomy & $23(6)$ & $31(8)$ & $23(7)$ & 0 & 8 & - \\
\hline $\begin{array}{l}\text { Uterine artery } \\
\text { and pedicle } \\
\text { ligation }\end{array}$ & $34(8)$ & $44(11)$ & $33(11)$ & 1 & 11 & - \\
\hline Intensive care & $152(38)$ & $152(38)$ & $149(48)$ & 3 & 3 & - \\
\hline
\end{tabular}

* on the basis of 30,614 deliveries, medical record as reference. 
Table 2 - Validity of the PMSI data for severe maternal morbid events (SMME): kappa score, sensitivity, specificity, positive predictive value (PPV) and negative predictive value (NPV) *.

\begin{tabular}{|c|c|c|c|c|c|}
\hline & Kappa & $\begin{array}{c}\text { Sensitivity } \\
\% \\
{[95 \% \mathrm{Cl}]} \\
\end{array}$ & $\begin{array}{c}\text { Specificity } \\
\% \\
{[95 \% \mathrm{Cl}]} \\
\end{array}$ & $\begin{array}{c}\text { PPV } \\
\% \\
{[95 \% \mathrm{CI}]} \\
\end{array}$ & $\begin{array}{c}\text { NPV } \\
\% \\
{[95 \% \mathrm{Cl}]} \\
\end{array}$ \\
\hline Eclampsia & 0,33 & $\begin{array}{c}85,0 \\
{[69,3-100,0]}\end{array}$ & $\begin{array}{c}99,7 \\
{[99,6-99,8]}\end{array}$ & $\begin{array}{c}20,2 \\
{[11,6-28,8]}\end{array}$ & $\begin{array}{c}99,9 \\
{[99,9-100,0]}\end{array}$ \\
\hline Pulmonary embolism & 0,73 & $\begin{array}{c}83,3 \\
{[68,4-98,2]}\end{array}$ & $\begin{array}{c}99,9 \\
{[99,9-100,0]}\end{array}$ & $\begin{array}{c}64,5 \\
{[47,6-81,3]}\end{array}$ & $\begin{array}{c}99,9 \\
{[99,9-100,0]}\end{array}$ \\
\hline Embolization & 0,72 & $\begin{array}{c}56,2 \\
{[47,6-64,5]}\end{array}$ & $\begin{array}{c}100,0 \\
-\end{array}$ & $\begin{array}{c}100,0 \\
-\end{array}$ & $\begin{array}{c}99,8 \\
{[99,7-99,8]}\end{array}$ \\
\hline revised results ${ }^{* *}$ & 0,98 & $\begin{array}{c}95,3 \\
{[91,6-98,9]}\end{array}$ & $\begin{array}{c}100,0 \\
-\end{array}$ & $\begin{array}{c}100,0 \\
-\end{array}$ & $\begin{array}{c}99,9 \\
{[99,8-100,0]}\end{array}$ \\
\hline Hysterectomy & 0,85 & $\begin{array}{c}74,2 \\
{[58,8-89,6]}\end{array}$ & $\begin{array}{c}100,0 \\
-\end{array}$ & $\begin{array}{c}100,0 \\
-\end{array}$ & $\begin{array}{c}99,9 \\
{[99,9-100,0]}\end{array}$ \\
\hline revised results ${ }^{* *}$ & 1 & $\begin{array}{c}100,0 \\
-\end{array}$ & $\begin{array}{c}100,0 \\
-\end{array}$ & $\begin{array}{c}100,0 \\
-\end{array}$ & $\begin{array}{c}100,0 \\
-\end{array}$ \\
\hline Ligation & 0,84 & $\begin{array}{c}75,0 \\
{[62,2-87,8]}\end{array}$ & $\begin{array}{c}99,9 \\
{[99,9-100,0]}\end{array}$ & $\begin{array}{c}97,6 \\
{[92,4-100,0]}\end{array}$ & $\begin{array}{c}99,9 \\
{[99,9-100,0]}\end{array}$ \\
\hline revised results ** & 96,5 & $\begin{array}{c}95,5 \\
{[89,4-100,0]}\end{array}$ & $\begin{array}{c}99,9 \\
{[99,8-100,0]}\end{array}$ & $\begin{array}{c}97,7 \\
{[93,2-100,0]}\end{array}$ & $\begin{array}{c}99,9 \\
{[99,8-100,0]}\end{array}$ \\
\hline Intensive care & 0,99 & $\begin{array}{c}98,0 \\
{[95,8-100,0]}\end{array}$ & $\begin{array}{c}99,9 \\
{[99,9-100,0]}\end{array}$ & $\begin{array}{c}98,0 \\
{[95,8-100,0]}\end{array}$ & $\begin{array}{c}99,9 \\
{[99,9-100,0]}\end{array}$ \\
\hline
\end{tabular}

* 4 centers, 2006-2007, on the basis of 30,607 deliveries, medical record as reference.

** : revised results after correction of procedure codes not specific to the obstetrical context 
Table 3 - Validity of the PMSI data for severe maternal morbid events (SMME) per center: sensitivity, specificity, positive predictive value (PPV) and negative predictive value (NPV) *

\begin{tabular}{cccccc} 
Deliveries & $\begin{array}{c}\text { Single } \\
\text { SMME in } \\
\text { PMSI }\end{array}$ & Sensitivity & Specificity & PPV & NPV \\
\hline $\mathrm{n}$ & $\mathrm{n}$ & $\%$ & $\%$ & $\%$ & $\%$ \\
& & {$[95 \% \mathrm{Cl}]$} & {$[95 \% \mathrm{Cl}]$} & {$[95 \% \mathrm{Cl}]$} & {$[95 \% \mathrm{Cl}]$} \\
\hline
\end{tabular}

\begin{tabular}{|c|c|c|c|c|c|c|}
\hline All centers & 30607 & 396 & $\begin{array}{c}78,7 \\
{[74,6-82,7]}\end{array}$ & $\begin{array}{c}99,7 \\
{[99,6-99,8]}\end{array}$ & $\begin{array}{c}79,3 \\
{[75,3-83,3]}\end{array}$ & $\begin{array}{c}99,7 \\
{[99,6-99,8]}\end{array}$ \\
\hline revised results * & & 465 & $\begin{array}{c}96,7 \\
{[94,9-98,4]}\end{array}$ & $\begin{array}{c}99,7 \\
{[99,6-99,8]}\end{array}$ & $\begin{array}{c}83,0 \\
{[79,6-86,4]}\end{array}$ & $\begin{array}{c}99,9 \\
{[99,9-100,0]}\end{array}$ \\
\hline Center 1 & 6555 & 74 & $\begin{array}{c}97,3 \\
{[93,6-100,0]}\end{array}$ & $\begin{array}{c}99,9 \\
{[99,8-99,9]}\end{array}$ & $\begin{array}{c}97,3 \\
{[93,6-100,0]}\end{array}$ & $\begin{array}{c}99,9 \\
{[99,8-99,9]}\end{array}$ \\
\hline revised results * & & 74 & $\begin{array}{c}97,3 \\
{[93,6-100,0]}\end{array}$ & $\begin{array}{c}99,9 \\
{[99,8-99,9]}\end{array}$ & $\begin{array}{c}97,3 \\
{[93,6-100,0]}\end{array}$ & $\begin{array}{c}99,9 \\
{[99,8-99,9]}\end{array}$ \\
\hline Center 2 & 10486 & 126 & $\begin{array}{c}84,4 \\
{[78,4-90,4]}\end{array}$ & $\begin{array}{c}99,9 \\
{[99,8-100,0]}\end{array}$ & $\begin{array}{c}94,4 \\
{[90,4-98,4]}\end{array}$ & $\begin{array}{c}99,8 \\
{[99,7-99,9]}\end{array}$ \\
\hline revised results * & & 141 & $\begin{array}{c}95,0 \\
{[91,4-98,6]}\end{array}$ & $\begin{array}{c}99,9 \\
{[99,8-100,0]}\end{array}$ & $\begin{array}{c}95,0 \\
{[91,4-98,6]}\end{array}$ & $\begin{array}{c}99,9 \\
{[99,8-100,0]}\end{array}$ \\
\hline Center 3 & 3970 & 38 & $\begin{array}{c}51,5 \\
{[39,4-63,6]}\end{array}$ & $\begin{array}{c}99,9 \\
{[99,8-100,0]}\end{array}$ & $\begin{array}{c}89,4 \\
{[79,6-99,2]}\end{array}$ & $\begin{array}{c}99,2 \\
{[98,9-99,5]}\end{array}$ \\
\hline revised results * & & 70 & $\begin{array}{c}97,0 \\
{[92,9-100,0]}\end{array}$ & $\begin{array}{c}99,9 \\
{[99,8-100,0]}\end{array}$ & $\begin{array}{c}94,2 \\
{[88,7-99,7]}\end{array}$ & $\begin{array}{c}99,9 \\
{[99,8-100,0]}\end{array}$ \\
\hline Center 4 & 9596 & 158 & $\begin{array}{c}75,4 \\
{[67,6-83,2]}\end{array}$ & $\begin{array}{c}99,3 \\
{[99,1-99,5]}\end{array}$ & $\begin{array}{c}57,4 \\
{[49,6-65,2]}\end{array}$ & $\begin{array}{c}99,7 \\
{[99,6-99,8]}\end{array}$ \\
\hline revised results * & & 181 & $\begin{array}{c}98,3 \\
{[95,9-100,0]}\end{array}$ & $\begin{array}{c}99,3 \\
{[99,1-99,5]}\end{array}$ & $\begin{array}{c}63,5 \\
{[56,5-70,5]}\end{array}$ & $\begin{array}{c}100,0 \\
-\end{array}$ \\
\hline
\end{tabular}

* 4 centers, 2006-2007, on the basis of 30,607 deliveries, medical record as reference.

${ }^{* *}$ : revised results after correction of procedure codes not specific to the obstetrical context 